\title{
COVID 19 - The Spanish Perspective
}

\author{
Enrique Pérez de la Sota ${ }^{1}$, Miguel Pinon ${ }^{2}$, Eduard Quintana ${ }^{3}$, and Carlos Mestres ${ }^{4}$ \\ ${ }^{1} 12$ th of October University Hospital \\ ${ }^{2}$ Hospital Universitario "Alvaro Cunqueiro" \\ ${ }^{3}$ Hospital Clínic \\ ${ }^{4}$ University Hospital Zurich
}

July 30, 2020

\begin{abstract}
COVID-19 hit hard worldwide. There has been an impact on global activity of cardiac surgery. Spain has been one of the hardest hit countries with one of the highest per population incidences and death. Cardiac surgical activity has suffered a negative impact all over the country. The following is an overview of the epidemiology and impact on resources, the caseload and surgical societal implemented recommendations, the description of the ECMO activity and nosocomial transmission among healthcare workers.
\end{abstract}

\section{Key words}

COVID-19; pandemic; cardiac surgery; perspective; Spain

\section{Introduction}

The COVID-19 pandemic has hit hard all over. The current situation is still complex. We will need time to evaluate the impact and consequences in the years to come. The price to pay will be insurmountable. Many ongoing social, economic and organizational changes will be profound and possibly irreversible. It will not be for good. Responsibilities for this medical and humanitarian disaster have to be defined. In any case, those responsible at local, regional, national or international level will likely never, as expected, pay for this (1).

The history of the pandemic is known. It enhanced the response of the community in different ways. A simple literature search using the term "COVID-19" yields (July 25, 2020) 35,054 citations from December 31, 2019 when China reported to the World Health Organization (WHO) the first epidemic cluster of an unknown low respiratory infection in humans at Wuhan (2). This was never seen in medical literature (3). The reasons of why this happened must be discussed in the future.

Cardiovascular surgeons participated in the care of COVID-19 patients like many other professionals, reconverted in emergency room or intensive care physicians, being in the front line. The pandemic represented a major disruption in cardiac surgical programmes worldwide.

WHO declared the outbreak a Public Health Emergency of International Concern (PHEIC) on January 30, 2020 raising to "very high" level on February 28. The new coronavirus, termed severe acute respiratory syndrome coronavirus 2 (SARS-CoV-2) by the International Committee on Taxonomy of Viruses (4). The coronavirus disease (COVID-19) was officially named in the International Classification of Diseases (ICD) on 11 February 2020 (5). The first three cases in Europe were confirmed in France, on January 24, 2020 (6). Thirty-six additional cases were soon confirmed Lombardy, Italy (7). 
A basic reproductive number $\left(\mathrm{R}_{0}\right)$ for COVID-19 of around 2-3, estimates a high rate of spread in the early stages of the epidemic. A $R_{0}>1$ indicates the likelihood of increasing infected numbers and that control measures are needed to limit the spread (8). Collaborative strategies were implemented worldwide with stress on strength surveillance and tracing to identify imported cases and avoid community transmission to reduce the disease burden and mitigate the devastating effects of the pandemic.

\section{The Spanish situation}

\section{Timeline}

First confirmation of positive SARS-CoV-2 was an imported tourist case in La Gomera, Canary Island on January 31 (9). Community transmission of the virus supposedly began in mid February (Figure 1).

\section{Lockdown}

Growth rates and the doubling time of the infection in the early phase, indicated that Spain and other European countries, needed extra containment measures to handle the situation. Physical distancing, quarantine, isolation, lockdown and curfew were considered all over.

On March 14, 2020, the Spanish government declared the State of Alarm, the legal enforcement to stop the constant flow of people (10). The previous day, 7,923 new cases had been reported. This was despite repeated warnings from the European Centres for Disease Prevention and Control on the high risk of transmission (11). Instead, the Spanish Government promoted a large demonstration in the capital city of Madrid (1). Other large gatherings were organized by different political parties in Madrid and other Autonomous Communities (CC. AA.). Of impact was also a large demonstration in the C.A. of Catalonia, with transfer of over 150,000 people across the French border who in the same day exposed the population of two countries. During this period, all non-essential professional activities were suspended. The only businesses that have remained open were pharmacies and basic food businesses. The freedom of movement of people was severely curtailed with drastic restrictions applied to public and private transport.

Congress approved the State of Alarm, and during its validity, the national government assumed the management of the national health system, in the form of a single command, taking over from the $17 \mathrm{CC}$. AA. This period was extended up to six times by decision of Congress, remaining in force until June 21 (12).

\section{Epidemiological data and health care resources}

The peak of daily cases was on March $20(10,845)$ and peak of deaths was on April 02 (950). On July 17, 260,255 cases were confirmed with 28,403 deaths, an $11.2 \%$ lethality slightly behind the UK, Italy, and France, according to the data provided by the Ministry of Health (MOH). Two of most populated CC. AA., Madrid (6,7 million) and Catalonia (7,6 million) were the most severely affected, according to aggregated data (72,168 and 62,057 confirmed cases, respectively).

By mid-July 2020, 125,797 patients required hospitalisation (165 last seven days), 11,721 were admitted to the ICU (11 the last week) with 28,409 deaths ( 8 the last week). The global number of deaths it is believed to be underestimated, due to the initial lack of testing, according to the excess mortality of any cause (57\%) from March 13 to May 22 (Daily mortality surveillance system - Monitoring of Mortality - MoMo 2020, Health Institute Carlos III) (13) (Figure 2).

Health care workers (HCW) were the population subgroup with the highest risk of infection, along with the elderly, reaching $20 \%$ of the global number of cases. On May 11, 40,961 HCW positive cases were reported to the National Network of Epidemiological Surveillance RENAVE (14) reaching 52,575 by June 25, as per the $\mathrm{MOH}$. Many retired doctors and $\mathrm{HCW}$ were recruited due to system overload.

The main area of system collapse was the intensive care. The latest official data regarding the provision of critical beds in our country dates from 2017, with 4,519 beds in public and 1,137 in private hospitals, according to the $\mathrm{MOH}$ (15). Contingency plans were drawn up, and intensive care capacity expanded acutely to more than double or even 7 -fold in some cases (16) with new ICU beds set up in libraries, rehabilitation 
facilities, operating rooms and recovery rooms. Madrid and Catalonia had almost triplicated their number of ICU beds, from an average of 600 to 1,500 on April 2 during the peak (from 460 to 1,528 in Madrid).

Specific intensive care beds for cardiac surgery are mostly included in the areas of intensive care and resuscitation; however, 13 independent monographic units have been identified (17) the availability of which has been seriously affected by the current crisis of COVID-19, responsible for $40 \%$ of the occupation in critical units, according to some estimates. Cardiac surgical programs suspended elective procedures aiming at reducing the burden on the health care system and increasing resources, mainly ventilators and ICU beds. Untested positive COVID-19 patients might have been then operated on. No information is available on eventual impact on outcomes.

Furthermore, most patients were reluctant to report to hospital facilities during the pandemic, as evidenced by up to a $40 \%$ reduction of percutaneous coronary interventions in acute coronary syndromes or $81 \%$ in structural procedures in Spanish centres (18).

With the "flattening of the curve," the numbers began to drop, the burden on the health care systems was alleviated, and resources were sufficient to restart elective procedures. However, safety is also a concern, and precautions should be extreme to avoid nosocomial SARS-CoV-2 transmission and ensure HCW protection. Even more, non-detected COVID patients undergoing cardiac surgery can jeopardize their prognosis, due to respiratory insufficiency and thrombo-hemorragic complications.

\section{Reopening}

The relief of the lockdown was carried out in accordance with the epidemiological diversity of the different regions. Four phases were defined (Phases 0 to 3), undertaken differentially depending on the epidemiological data and the availability of resources in the autonomous communities. The objective criteria for the CC. AA. to start de-escalation were to have access to or capacity to install, within a maximum period of five days, between 1.5 and 2 intensive care beds, and between 37 and 40 beds for acute patients per 10,000 inhabitants (19). The major challenge of cardiac surgery units at this time is to resume elective activity, based on safety criteria and rational use of resources that allow handling eventual successive outbreaks.

Impact on the global activity of cardiac surgery

\section{Cardiac surgery in Spain: an overview}

The National Registry of Interventions of the Spanish Society of Cardiovascular and Endovascular Surgery (SECCE) summarizes the annual activity and outcomes in Spain in the public and private spheres and reflects the state of the art of the specialty in our country. The latest publication corresponds to the year 2018 (20), with 34,318 procedures performed in 62 centers, of which 23,141 were major cardiac operations (20,717 with extracorporeal circulation). Among major acquired diseases (21,082 procedures), isolated valve surgery predominates, followed by coronary artery bypass surgery. Transcatheter procedures are included in the registry. The average number of interventions per center was $551(66-2,166)$ with a wide dispersion between hospitals ( $55 \%$ of centers performed between 300 and 600 interventions), also highlighting significant regional variability, undoubtedly related to the Spanish political and administrative structure.

\section{Cardiac Surgery during the pandemic}

The State of Alarm imposed extremely harsh restrictions on the mobility of the citizens (mandatory house confinement) and on educational, commercial and national and international transport activity, closed the national borders and established the possibility of requisitioning of goods. These were amongst the harshest conditions worldwide and, in practice, a national lockdown.

The $\mathrm{MOH}$ took over the command of operations, granting minor management possibilities to regional and local public administrations within their sphere of competence. This included privately owned hospitals.

The MOH, autonomic authorities of Health and Management Directions of health centers organized a contingency plan for Cardiovascular Surgery services. In practice, all of material and human health resources 
were exclusively devoted to fighting the pandemic. Elective activity was cancelled. The surgical services moved out of the regular facilities and dedicated operating rooms converted into intensive care for COVID-19 patients.

As stated, the Spanish Society of Cardiovascular and Endovascular Surgery (SECCE) reacted very quickly issuing a number of Recommendations (21), with specific instructions and action algorithms guiding the contingency plan for cardiovascular surgery services. It was then ensured: a) the correct care of urgent and emerging patients, b) the organization of a list of preferential patients and the temporal criteria for surgery, c) the justified and safe delay of the patients for elective surgery whose illness and clinical situation allow it and d) the specific application of ECMO programs in the context of COVID-19 (18).

In the regions hardest hit by the pandemic, such as CC. AA. of Madrid and Catalonia as per national statistics and the Johns Hopkins Coronavirus Resource Center (22), attempts were made to reboot the system in the first weeks of May. Strict infection screening protocols and "clean circuits" were established for elective patients, leading to a very slow and extremely cautious restart of activity.

The changes in the organization of health care imposed by the pandemic has had an impact on worldwide surgical activity, although its quantification is difficult at the present time since at the time of writing this manuscript, we are still fighting against the virus. The experience lived in the hardest months of the crisis indicates a significant decrease in activity; as an example, in the C.A. of Madrid, about 150 patients underwent surgery in March and April, almost entirely emergent and urgent. According to the SECCE registry (21), the volume in this Community in 2018 was 4,206 major cardiac operations, which means that, in that two-month period and under normal conditions, about 750-800 patients would have undergone cardiac surgery in Madrid.

A careful analysis of the national data, from government sources of from our scientific society, will allow us to estimate in the near future the final impact of the pandemic on the global activity of cardiac surgery. By now, there are only initiatives in a smaller scope at the regional level, which shortly will offer many precise data on the activity of cardiac surgery in the COVID era.

\section{ECMO in COVID-19 patients}

The urgent need to treat critically ill patients with an unknown evolution has forced cardiovascular surgeons to decide whether or not to implant an ECMO system when the scientific evidence available, in the context of COVID-19, was sparse and weak. Only a few published cases from China were available at the beginning of the pandemic $(23,24)$.

To add some confusion, concerns were raised about the possible deleterious effect of ECMO in this disease; it is know that during ECMO support there are substantial decreases in number and function of some lymphocyte populations, as well as consistently high IL-6 concentrations inversely correlated with survival. Prudence advised to consider the immunological status of patients when selecting ECMO candidates and seriously tracking both lymphocyte count and IL-6 during support.

\section{SECCE societal positioning}

As per issued societal recommendations (21) Cardiovascular Surgery services, in conjunction with Intensive Care, could offer specialized care at the highest level through the use of temporary mechanical support (V-V and V-A ECMO) in COVID-19 patients with severe adult respiratory distress syndrome (ARDS) or cardiomyopathy refractory to the conventional treatment. With this official positioning, the medical attention to the critically ill patients took precedence over possible concerns about the suitability of the therapy in this disease.

More specifically, it was recommended:

* Adaptation of the different ECMO programs for their priority use in the pandemic, also guaranteeing adequate health care in the reference area. 
* To establish criteria for ECMO support and the exclusion and contraindication criteria for COVID-19 patients.

* To restrict the number of ECMO-involved professionals to the minimum necessary.

* To enroll patients in the ECMO-COVID-19 Registry specifically created by the SECCE.

The different ECMO groups were organized to offer the assistance required at all times according to the impact of the pandemic and availability of resources.

\section{ECMO Registries in COVID-19 patients}

EuroECMO-COVID Survey :

It is an initiative of the Steering Committee of the European chapter of the Extracorporeal Life Support Organization (Euro-ELSO) to obtain weekly information on the use of ECMO in European and Israel centers in complicated COVID-19 patients. The survey started on March 15, 2020; as of July 17, and with 1,387 patients collected, the survey reflected 160 ECMO implants in 26 centers in Spain, ranking third in Europe in number of implants, behind France (367 devices) and Germany (165 devices).

ECMO-COVID Spanish Registry :

An ECMO Implant Registry for COVID-19 patients (coordinator: Dr. Mario Castaño, León, Spain), was created and is managed by the SECCE and its Mechanical Circulatory Support Working Group.

Based on the EuroECMO-COVID Survey and directly exportable to it, the Spanish registry is somewhat more ambitious. It includes analytic parameters and prognostic severity markers (D-dimer, procalcitonin, C-reactive protein, ferritin, etc.) collected during the time of ECMO support as well as other in-ICU management variables. Altogether 100 variables are collected in a secure database accessible online, allowing the inclusion of every patient and updates during follow-up.

Data collection started at the beginning of April. As there are still newly diagnosed cases every day, the registry remains open and there are no preliminary analyses or provisional data. The results will be published in the near future. We can now give only an incomplete view of the information collected, not in the form of official publication.

As of June 30, the registry collected more than 110 patients from 24 different centers; $90 \%$ of the cases were $\mathrm{V}-\mathrm{V}$ ECMO implanted with the femoral-jugular configuration in two-thirds of the cases. The configuration was changed to V-A ECMO or upgraded (V-VA or VV-A) in up to $10 \%$ of patients, due to oxygenation problems or ventricular failure. The indication was ARDS/pneumonia in almost $90 \%$ of patients; the remaining corresponded to myocarditis, heart failure, barotrauma, or an association of them.

Today, more than $50 \%$ of patients have been successfully weaned from ECMO and almost $20 \%$ more are still on support; of all with completed follow-up, $55 \%$ were discharged from the hospital. The closing date of the registry has yet to be decided and therefore the final data of each patient are still not available.

Nosocomial SARS-Cov-2 transmission to cardiovascular surgery patients and healthcare personnel in Spain

Although cardiac surgical volumes have decreased worldwide, the need to continue to offer surgery, despite the coexistence of SARS-COV-2 within the hospital and beyond, becomes evident.

Preliminary reports of outcomes of thoracic surgery (25) and a variety of other surgical interventions points at a dramatic increase of postoperative mortality outside prediction. Although not reported, most likely COVID-19 has further negative impact in postoperative outcomes after cardiovascular surgery.

Transmission of SARS-COV-2 to HCW and nosocomial infection to healthy patients remain an undesired possibility $(26,27)$. Currently, there are no proven therapies to treat COVID-19 disease or to prevent its 
development once infection is acquired. Thus, it all comes down to develop a defensive line by means of extended measures.

In May 2020, a voluntary survey exploring the impact of the current pandemic was circulated amongst cardiovascular surgeons in Spain. Data from 13 university associated public healthcare centers offer a snapshot during the first pandemic wave. All those but one were appointed as regional COVID-19 referral institutions. Several aspects have been universal such as a steep decrease in the departmental activity with almost exclusive delivery of urgent or emergency operations. In $80 \%$ of centers cardiovascular surgery ICUs admitted COVID19-infected patients. Around $50 \%$ relocated their cardiac surgery patients to other units creating a newly design clean path for surgical patients away from COVID-19 cases.

Concerning preparation for the pandemic, around $20 \%$ of colleagues felt that their institutions failed in providing enough timely information regarding the developments. In fact, more than $80 \%$ of personnel undertook the necessary training to face COVID-19 cases after the admission of the first infected patients. Around $40 \%$ felt that their institutions did not provide them with enough PPE as deemed necessary by the Centers for Disease Control and Prevention (CDC) (mostly referring to the lack of FFP2 or FFP3 at any point outside the ICU environment).

In terms of surveillance of cardiovascular surgery personnel health status, most of the 13 responders carried regular COVID-19 swabs to surgeons. However, it is known that to a greater extend throughout Spain screening to HCW at the peak pandemic (sometimes even with symptoms suggesting SARS-Cov-2 infection) was not offered. Notably, newly admitted patients facing cardiac surgery had swab testing preoperatively. In $2 / 13(15 \%)$ centers cardiac surgeons were relocated to ICU primary physician positions whilst the other centers had their ICUs managed mainly by anesthesiologists. Four out of $13(30 \%)$ of centers had at least one staff cardiovascular surgeon infected with SARS-CoV-2 and 2/13 $(15 \%)$ had at least one trainee infected during at the time of the survey. About anesthesia personnel dedicated to cardiac surgery $5 / 13(38 \%)$ centers had infected colleagues. In summary, the rate of infected healthcare cardiovascular surgery personnel has not been anecdotal, although difficult to attribute entirely to in-hospital infections. The suspicion is that the majority may have been infected at workplace -State of Alarm was declared - despite a significant decrease of surgery volume thus pointing at cross-contamination between personnel.

The impact of SARS-CoV-2 in patients undergoing cardiac surgery has not been minor. Although hard to distinguish from nosocomial acquisitions vs community-acquired disease (before admission) almost half of centers performed surgery in at least one COVID-19 patient (range 1-10) since the pandemic was declared. The observed mortality in this sample ranged from $9 \%$ to $60 \%$, once COVID-19 affects a patient undergoing cardiovascular surgery. Important to mention, the transplant activity decreased significantly (number of offers also decreased) with some centers formally closing the program temporarily under the threat of a potential negative impact of infection on transplant patients.

In view of the above mentioned, when facing a surgical emergency it seems wise to adopt further protective measures despite the absence of COVID-19 symptoms or exposure to known cases. The proposal is extending preoperative evaluation to other laboratory tests such as ferritin, C-reactive protein and pay attention for the presence of leukopenia. Such abnormal tests and/or pulmonary infiltrates -beyond pulmonary edemashould raise SARS-CoV-2 suspicion and motivate full PPE and FFP3 mask use. If there are no laboratory or imaging data suggesting the presence of SARS-CoV-2, the use of FFP2-3 and a regular surgical mask on top seems advisable during this pandemic (for protection from patients and for protection from/of other HCW nearby). The reason to wear a regular surgical mask on top of a valved high-filtering mask is that HCW can be asymptomatic carriers and we should protect our surrounding colleagues from ourselves (valved-FFP3 masks do not offer protection to those in close contact). In addition, a delay of 30 minutes since intubation to operating room access - for those not involved with the airway procedure - seems advisable if not wearing full PPE $(28,29)$. All measures and efforts need to be in place to avoid cross-contamination of secondary patients or HCW. Some of those measures have been adopted by Spanish centers and remain now.

In our opinion, the use of surgical masks alone in the hospital during this pandemic either inside or outside 
the operating room seems questionable and unsafe. Mortality and complications arising from a negative - direct or indirect - impact of the pandemic amongst cardiovascular diseases has also been reported in Spain (18). The need to increase the practice of cardiovascular surgery to regular volume is inevitable and necessary despite SARS-CoV-2 is expected to remain in the population until general immunity is acquired or an effective vaccine available. For this reason, a change in paradigm of conventional protective measures seems necessary at multiple ends (30) and particularly true as we are currently seeing a new escalation of SARS-CoV-2 cases across the country. We are in a critical moment with the need of a roadmap to resume elective surgery without putting the patients and ourselves at further risk. Preoperative extended screening including swab tests, routine laboratory tests (including ferritin, D-dimer and leucocyte count) and chest Xray obtained 2-3 days prior to an elective procedure, have become routine practice in Spain to help decrease the risk of postoperative mortality, complications and in-hospital transmissions of SARS-CoV-2.

\section{Discussion}

This Spanish perspective is a very small contribution. Pandemics are, by definition, of worldwide dimensions and COVID-19 is one generating still unknown damage and damping social and economic development. Other specialties are now reporting diverse experiences from most of affected countries (1), aiming at describing the impact of the SARS-CoV-2 on organ failure.

However, the contributions of physicians and HCW from all over the world to understand, diagnose and treat the disease, COVID-19, are just a small part of a problem of extraordinary dimensions. Amidst the pandemic, it is time to start thinking of seeking for responsibilities at the highest level. Because of such a worldwide problem, many professionals around the world are voicing what could have been done in preventing the spread of the disease. It is clear that this pandemic hit countries and governments unprepared. However, the governmental actions widely differed contributing to diverse degrees of local spread despite the repeated warnings of the WHO (10).

The very recent contribution of Chaudhry et al (30), analysing data from the top 50 countries ranked by the number of cases, literally concluded that "the findings of this country level analysis on COVID-19 related health outcomes suggest that low levels of national preparedness, scale of testing, as well as population characteristics such as obesity, advanced age and higher per capita GDP are associated with increased national case load and mortality". This is critical to understand the behavior by country and region. Low levels of national preparedness are only related to government actions, fundamental in the control of local extension of the disease. This includes, among other, the timing of implementation of measures. In the case of Spain is known through each and every media, that the Spanish government did not prepare for the epidemic. As it is also literally stated in the editorial by Carriazo et al (1), it failed to limit public mass gatherings and astonishingly and actively promoted a large demonstration in Madrid on 8 March that was led by Deputy Prime Ministers Carmen Calvo and Nadia Calviño and by Ministers Irene Montero, Fernando Grande Marlaska, Isabel Celaá, Arancha González Laya and Carolina Darias. A number of them and others like the wife of the Prime Minister, became infected (31). Some of the cabinet members as Deputy Prime Minister Pablo Iglesias did not follow the recommendations in terms of confinement (32). The attitude of the Public Health representative, Fernando Simón, without opposing the large demonstration or in other words, supporting its go-ahead, led to the country ranking highest in deaths per capita. In the case of Spain, more blatant is that nobody publicly said a word about the MOH 2007 measures addressing a flu pandemic, published after the SARS of 2002 (33). Remember, those responsible have names like this article's authors.

The medical community, physicians and HCW, have done their duty and beyond. Many have stayed on the road. Cardiac surgery has also responded, as it is clear from this special issue of the Journal. As we have also recently said (34), it is time for those responsibly to honestly (sic) addressing the society. The time hopefully will come when we must discuss about accountability, legal responsibilities, and eventual criminal charges of those responsible for the disaster due to inappropriate handling of the crisis (1). Let us see what comes; however, as also stated by us (34), what we foresee is living with uncertainty, mortality and more state security protocols, with the pandemic being an excuse for absolute control of our lives. It also will be the need to guarantee the protection of citizens facing abuse from the State. 


\section{References}

1. Carriazo S, Kanbay M, Ortiz A. Clin Kidney J 2020; 13:274-280.

2. WHO Timeline - COVID-19 2020 [Available from: https://http://www.who.int/news-room/detail/2704-2020-who-timeline - covid-19?gclid=Cj0KCQjw6ar4BRDnARIsAITGzlCP3ooLkq0332yYaqBPjSMfK-6YRlfL71J6i8s__ZdH8zFahKkNCC. AA.jsNEALw_wcB. Updated version June 29, 2020.

3. https://pubmed.ncbi.nlm.nih.gov/ last accessed July 24, 2020.

4. Gorbalenya AE, Baker SC, Baric RS, et al. The species Severe acute respiratory syndrome-related coronavirus: classifying 2019-nCoV and naming it SARS-CoV-2. Nat Microbiol 2020; 5:536-544.

5. WHO. Naming the coronavirus disease (COVID-19) and the virus that causes it 2020 [Available from: https:/http://www.who.int/emergencies/diseases/novel-coronavirus-2019/technicalguidance/naming-the-coronavirus-disease-(covid-2019)-and-the-virus-that-causes-it.

6. Stoecklin SB, Rolland P, Silue Y, et al. First cases of coronavirus disease 2019 (COVID-19) in France: surveillance, investigations and control measures, January 2020. Eurosurveillance 2020; 25(6):2000094.

7. Grasselli G, Pesenti A, Cecconi M. Critical Care Utilization for the COVID-19 Outbreak in Lombardy, Italy: Early Experience and Forecast During an Emergency Response. JAMA 2020; 323:1545-1546.

8. Trilla A. One world, one health: The novel coronavirus COVID-19 epidemic. Med Clin (Barc) 2020; 154:175-177

9. https://www.redaccionmedica.com/secciones/sanidad-hoy/espana-confirma-su-primer-caso-depositivo-por-coronavirus-de-wuhan-7264.

10. Ministerio de la Presidencia RclCyMD. Real Decreto 463/2020. Boletín Oficial del Estado (BOE) [Internet]. 2020; 67:[25390-400 pp.]. Available from: https://http://www.boe.es/eli/es/rd/2020/03/14/463.

11. European Centres for Disease Control and Prevention. ECDC assessment of the COVID-19 situation in Europe as of 2 March 2020. https://www.ecdc.europa.eu/en/news-events/ecdc-assessment-covid-19situation-europe-2-march-2020 last accessed July 24, 2020.

12. Real Decreto-ley $21 / 2020$, de 9 de junio, de medidas urgentes de prevención, contención y coordinación para hacer frente a la crisis sanitaria ocasionada por el COVID-19. 2020. 163:[38723-52 pp.]. Available from: https://www.boe.es/eli/es/rdl/2020/06/09/21.

13. España AdlcdC-epsnalRhedme. Instituto de Salud Carlos III. Red Nacional de VigilanciaEpidemiológica.Available from: https://momo.isciii.es/public/momo/dashboard/momo_dashboard.html.

14. https://www.isciii.es/QueHacemos/Servicios/VigilanciaSaludPublicaRENAVE/EnfermedadesTransmisibles/Document

15. Estadística de Centros Sanitarios de Atención Especializada. Indicadores hospitalarios. Serie 2010-2017. [Publicación en Internet]. Madrid: Ministerio de Sanidad, Consumo y Bienestar Social. 2019. Available from: https://www.mscbs.gob.es/estadEstudios/estadisticas/estHospiInternado/inforAnual/homeESCRI.htm.

16. Arango C. Lessons Learned From the Coronavirus Health Crisis in Madrid, Spain: How COVID-19 Has Changed Our Lives in the Last 2 Weeks. Biol Psychiatry . 2020 Apr 8:S0006-3223(20)31493-1. doi: 10.1016/j.biopsych.2020.04.003.

17. Martín MC, León C, Cuñat J, et al . Recursos estructurales de los Servicios de Medicina Intensiva en España. Medicina Intensiva2013; 37:443-451.

18. Rodríguez-Leor O, Cid-Álvarez B, Ojeda S, et al. Impacto de la pandemia de COVID-19 sobre la actividad asistencial en cardiología intervencionista en España. REC Interv Cardiol 2020;2:82-9.

19. Sanidad. Md. Orden SND/387/2020, de 3 de mayo, por la que se regula el proceso de cogobernanza con las comunidades autónomas y ciudades de Ceuta y Melilla para la transición a una nueva normalidad. 2020. p. 31113.https://www.boe.es/buscar/pdf/2020/BOE-A-2020-4792-consolidado.pdf

20. Cuerpo G, Carnero M, Hornero F, et al. Cardiovascular surgery in Spain performed in 2018. National registry of interventions of the Spanish Society of Thoracic-Cardiovascular Surgery. Cir Cardiov 2019; 26:248-264. https://doi.org/10.1016/j.circv.2019.10.002.

21. Garrido Jiménez JM, Barquero Aroca JM, Valderrama Marcos JF, et al. Spanish Society of Cardiovascular and Endovascular Surgery recommendations for the COVID-19 pandemic. Cir Cardiov 2020; 27:86-92 https://doi.org/10.1016/j.circv.2020.04.002.

22. https://coronavirus.jhu.edu/map.html last accessed July 24, 2020. 
23. Li X, Guo Z, Li B, et al. Extracorporeal Membrane Oxygenation for Coronavirus Disease 2019 in Shanghai, China.ASAIO J 2020; 66:475-481.

24. Zeng Y, Cai Z, Xianyu Y et al. Prognosis when using extracorporeal membrane oxygenation (ECMO) for critically ill COVID-19 patients in China: a retrospective case series. Crit Care . 2020; 24:145-148.

25. Li YK, Peng S, Li LQ, et al. Clinical and Transmission Characteristics of Covid-19 - A Retrospective Study of 25 Cases from a Single Thoracic Surgery Department. Curr Med Sci 2020; 40:295-300.

26. Alhazzani W, Moller MH, Arabi YM, et al. Surviving Sepsis Campaign: guidelines on the management of critically ill adults with Coronavirus Disease 2019 (COVID-19). Intensive Care Med 2020; 48: e440e469.

27. Tan Z, Phoon PHY, Zeng LA, et al. Response and Operating Room Preparation for the COVID-19 Outbreak: A Perspective from the National Heart Centre in Singapore. J Cardiothorac Vasc Anesth. 2020 Mar 29. pii: S1053-0770(20)30300-1.

28. van Doremalen N, Bushmaker T, Morris DH, et al. Aerosol and Surface Stability of SARS-CoV-2 as Compared with SARS-CoV-1. N Engl J Med 2020; 382:1564-1567.

29. Morawska L, Cao J. Airborne transmission of SARS-CoV-2: The world should face the reality. Environ Int . 2020 Apr 10; 139:105730. doi: 10.1016/j.envint.2020.105730.

30. Chaudhry R, Dranitsaris G, Mubashir T et al. A country level analysis measuring the impact of government actions, country preparedness and socioeconomic factors on COVID-19 mortality and related health outcomes, EClinicalMedicine (2020), https://doi.org/10.1016/j. eclinm.2020.100464.

31. https://www.lavanguardia.com/politica/20200314/474143950520/begona-gomez-pedro-sanchezesposa-moncloa-coronavirus-covid-19.html. Last accessed 28 July

32. https://www.infobae.com/america/mundo/2020/03/14/pablo-iglesias-reconocio-que-violo-lacuarentena-por-pedido-de-pedro-sanchez/. Last accessed 28 July

33. Medidas no farmacológicas para responder a la pandemia de gripe fases 4, 5 y 6 plan nacional de preparación y respuesta ante una pandemia de gripe. Septiembre 2007. https://www.mscbs.gob.es/ciudadanos/enfLesiones/enfTransmisibles/docs/AnexoXIII_MedidasNoFarm.pdf.

34. Mestres CA. COVID-19: A pandemic of values and more. Gastroenterol Hepatol 2020; 43:385-386.

\section{Funding}

This study is not funded

\section{Data sharing}

The authors declare that the data collected was gathered from available databases

\section{Declaration of Competing Interest}

The four authors declare no financial interest

\section{Hosted file}

20200728-COVID-JOCS-The Spanish Perspective-Figure 1.docx available at https://authorea.com/ users/347498/articles/473158-covid-19-the-spanish-perspective

\section{Hosted file}

20200728-COVID-JOCS-The Spanish Perspective-Figure 2.docx available at https://authorea.com/ users/347498/articles/473158-covid-19-the-spanish-perspective 


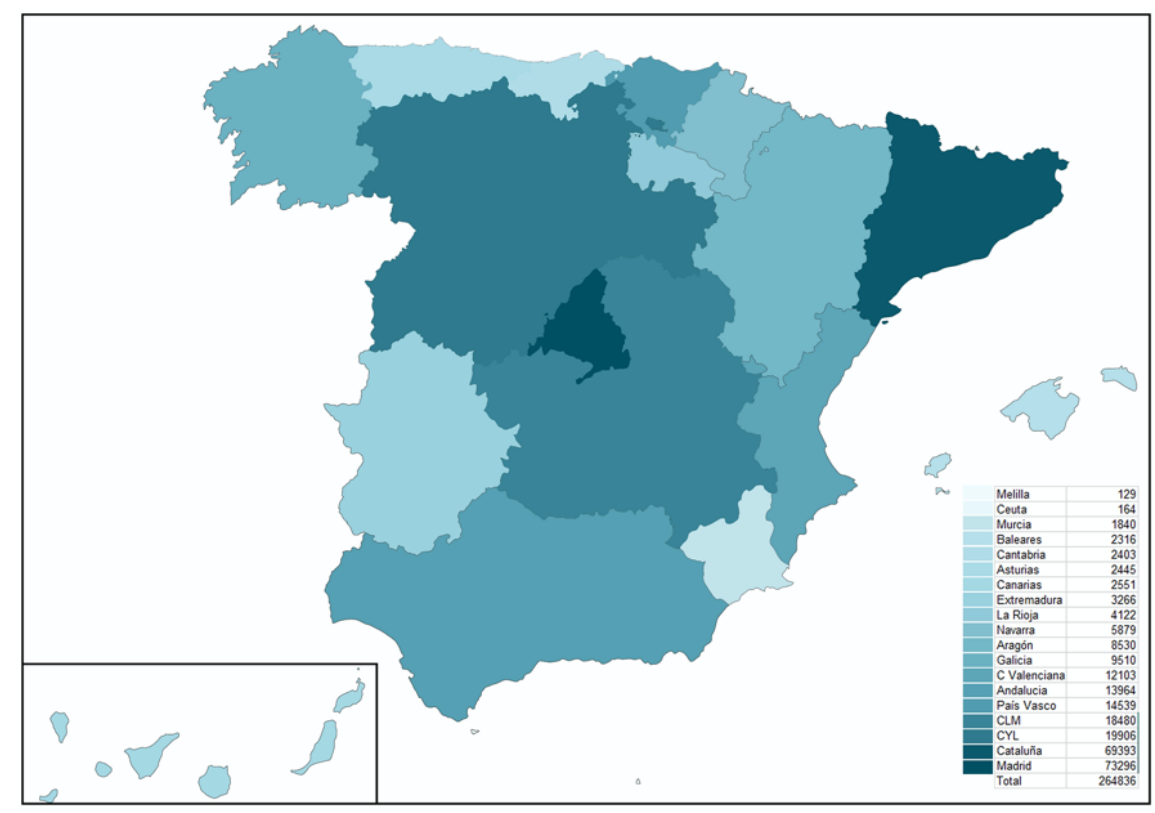

